\title{
Coastal observing and forecasting system for the German Bight - estimates of hydrophysical states
}

\author{
E. V. Stanev ${ }^{1}$, J. Schulz-Stellenfleth ${ }^{1}$, J. Staneva ${ }^{1}$, S. Grayek ${ }^{2}$, J. Seemann ${ }^{1}$, and W. Petersen ${ }^{1}$ \\ ${ }^{1}$ Institute of Coastal Research, Helmholtz-Zentrum Geesthacht (HZG), Max-Planck-Strasse 1, 21502 Geesthacht, Germany \\ ${ }^{2}$ Institute for Chemistry and Biology of the Sea (ICBM), University of Oldenburg, Carl-von-Ossietzky-Strasse 9-11, \\ 26111 Oldenburg, Germany
}

Received: 9 March 2011 - Published in Ocean Sci. Discuss.: 20 April 2011

Revised: 21 July 2011 - Accepted: 8 August 2011 - Published: 14 September 2011

\begin{abstract}
A coastal observing system for Northern and Arctic Seas (COSYNA) aims at construction of a long-term observatory for the German part of the North Sea, elements of which will be deployed as prototype modules in Arctic coastal waters. At present a coastal prediction system deployed in the area of the German Bight integrates near real-time measurements with numerical models in a preoperational way and provides continuously state estimates and forecasts of coastal ocean state. The measurement suite contributing to the pre-operational set up includes in situ time series from stationary stations, a High-Frequency (HF) radar system measuring surface currents, a FerryBox system and remote sensing data from satellites. The forecasting suite includes nested 3-D hydrodynamic models running in a dataassimilation mode, which are forced with up-to-date meteorological forecast data. This paper reviews the present status of the system and its recent upgrades focusing on developments in the field of coastal data assimilation. Model supported data analysis and state estimates are illustrated using HF radar and FerryBox observations as examples. A new method combining radial surface current measurements from a single HF radar with a priori information from a hydrodynamic model is presented, which optimally relates tidal ellipses parameters of the 2-D current field and the M2 phase and magnitude of the radials. The method presents a robust and helpful first step towards the implementation of a more sophisticated assimilation system and demonstrates that even using only radials from one station can substantially benefit state estimates for surface currents. Assimilation of FerryBox data based on an optimal interpolation approach using a Kalman filter with a stationary background covariance ma-
\end{abstract}

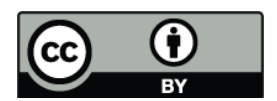

Correspondence to: E. V. Stanev (emil.stanev@hzg.de) trix derived from a preliminary model run which was validated against remote sensing and in situ data demonstrated the capabilities of the pre-operational system. Data assimilation significantly improved the performance of the model with respect to both SST and SSS and demonstrated a good skill not only in the vicinity of the Ferry track, but also over larger model areas. The examples provided in this study are considered as initial steps in establishing new coastal ocean products enhanced by the integrated COSYNA-observations and numerical modelling.

\section{Introduction}

The North Sea is one of the best studied shelf systems, the southern part of it including the German Bight (Fig. 1) provides an excellent and well sampled natural tidal laboratory. Oscillations associated with the propagation of a Kelvin wave around an amphidromy at $55.5^{\circ} \mathrm{N}, 5.5^{\circ} \mathrm{E}$ range from $2.5 \mathrm{~m}$ (Islands Borkum and Sylt) to $3.5 \mathrm{~m}$ (the Elbe River mouth), i.e., the region is exposed to upper mesotidal conditions. Under the dominating influence of tides, wind, wind waves and fresh water fluxes from Rhine, Ems, Weser and Elbe Rivers a specific coastal water mass is formed, which is rich in nutrients and suspended particulate matter (SPM), thereby supporting a diverse flora and fauna. What makes the scientific understanding still difficult is the high complexity of the systems, lack of reliable long-term observations and optimal observation strategies.

In the near coastal areas satellite altimeters and Argo floats, which present the major source of data for the open ocean operational modelling become less applicable because of errors in altimeter data and shallow depths limiting the operability of Argo floats. These problems explain the need for

Published by Copernicus Publications on behalf of the European Geosciences Union. 


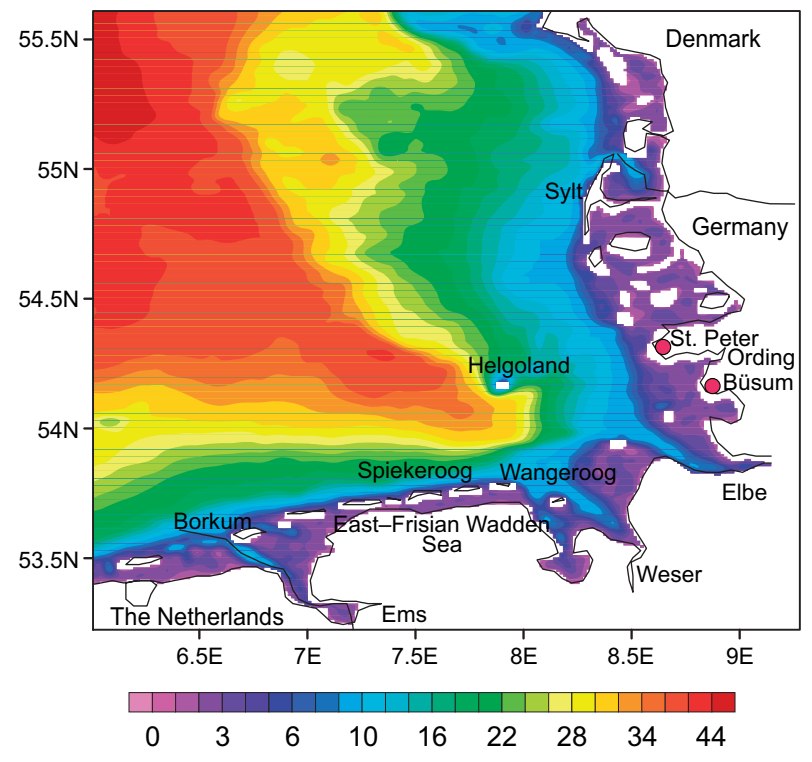

Fig. 1. Topography of the German Bight. Depths are in (m).

collecting new data capturing dynamical response of the inner shelf circulation to local meteorological and open-ocean forcing. Such coastal-ocean-specific data could be used both for calibration of coastal altimetry with independent estimations, as well as useful complementing information to the conventional open ocean observations.

Illustration of the use of some newly available data from High-Frequency (HF)-radar and FerryBox to improve quality of coastal ocean state estimates is the first objective of the present work.

It is well known that differences between surface current velocities from HF-radars and other observation platforms exist due to: (1) measurement errors, (2) limitation in vertical, (3) averaging etc. The question about consistency of HF radar data with other available observations needs also to be clarified. Similar is the situation with the FerryBox data: conventional satellites measure the skin temperature, while a flow-through FerryBox system samples water 4 to $6 \mathrm{~m}$ below the surface. To put the above issue in the context of validation and data assimilation is the second objective of the present paper.

Integrating real-time measurements into a pre-operational coastal prediction system contributes not only to solving a number of practical tasks, but stimulates research and provides new knowledge. The Coastal Observing System for Northern and Arctic Seas (COSYNA) is a recent activity in Germany recognising the need as well as the challenge to set up an operational, integrated observational system for the German shelf. This activity requires national and international cooperation, and provides an important infrastructure enabling the German contribution to International programmes such as COASTAL GOOS, GEOSS, GEOHAB and GMES.

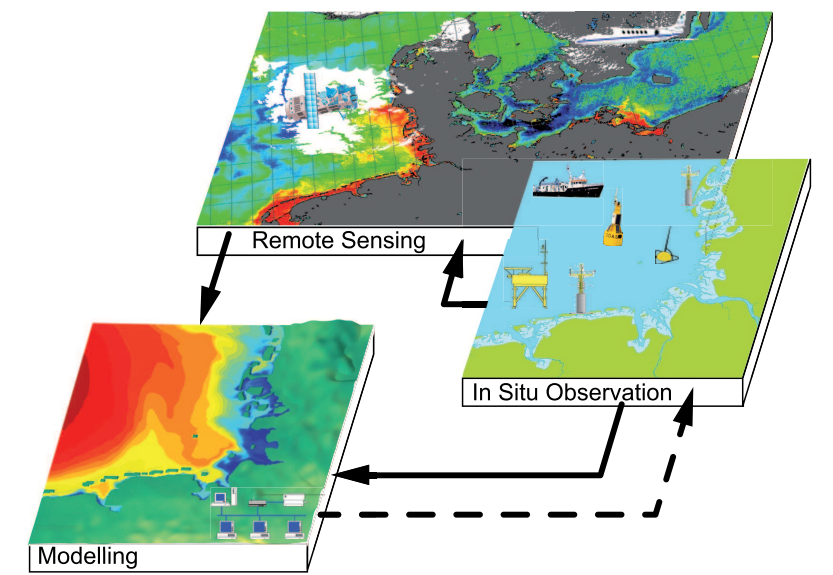

Fig. 2. Observation and modelling suite. The arrows illustrate the flow of information between in situ, remote sensing observations and numerical models. Dashed arrow illustrates possible contribution of models in optimising observational systems.

Operational activities in the global ocean (one example of them is GODAE, see Bell et al., 2009 and papers in the same issue) have demonstrated the value of integration of observations and numerical modelling. Recently there is also a trend of developing systematic observation programmes with an important forecasting component in the coastal ocean (see De Mey and Proctor, 2009 and the references in this Special Issue). Some very positive examples are emerging, as for instance the Ocean Observatories Initiative in the US (Schofield and Glenn, 2004; Seim, 2008; Glenn and Schofield, 2009, see other papers in that volumes). One important focus in the recent European COastal Sea Operational Observing and Forecasting System Project (ECOOP) with a participation of 72 institutions (see contributions to the present special issue) was on synergy between coastal forecasting and newly available data and methodologies (a step towards next generation forecasting systems). On the road of enhancing the exploitation of newly available near realtime data and improving the quality of coastal ocean forecasting research teams from the Universities of Sofia, Liege and Oldenburg, as well as the GKSS Research Centre initiated efficient cooperative research activities described by Staneva et al. (2009), Grayek et al. (2011) and Barth et al. (2010, 2011). National efforts have also contributed to the development in this field, one example is the observing system in Liverpool Bay (Proctor and Howarth, 2008).

COSYNA is a combination of in situ observations, remote sensing and numerical modelling (Fig. 2). Parameters monitored cover a wide range of interconnected processes including water and atmospheric physics, sediment transport, geochemistry and biology. A wide horizontal and vertical coverage of the system ranging from the benthic boundary layer, through the water column to the water-air interface and from the near coastal to open-sea waters enables a unique 
monitoring device with a new quality of data collection and transmission.

COSYNA aims at a synoptic view of the Southern North Sea and will significantly enhance our forecast capabilities by reducing the large uncertainties within state-of-the-art models. Melding data with models, which constitutes an essential part of the research in this framework enables an objective analysis of the environmental state.

The third objective of present paper is to describe some achievements started in the frame of ECOOP and continuing now in the frame of the National COSYNA Project in bringing together observations and numerical modelling in the coastal ocean. We first describe in Sect. 2 the observational system with a focus on data used in the present study, followed by a description of the modelling system in Sect. 3. Pre-operational applications focused on HF-radars and FerryBox data are described in Sects. 4 and 5, followed by short conclusions.

\section{Observational system}

The COSYNA concept uses spatially distributed platforms with a multitude of sensors operating in a coherent way. Presently, it consists of the following observation subsystems: FerryBox operating on fixed routes, as well as stationary, fixed stations in the Wadden Sea, wave rider buoys, HF-radar and X-band wave radar stations, remote sensing reference stations and satellite observations of the German Bight. These sub-systems are complemented by regular cruises with ships and profiling instruments. In the following we will describe briefly the platforms providing data for the present study focusing on FerryBox and HF radars.

\subsection{In situ observations}

FerryBox is an autonomous measurement and data logging and transmission system which operates continuously while the carrying ship is underway (Petersen et al., 2007, 2011). Measurements are made using devices which are either in direct contact with or sample from a continuous flow of seawater (flow-through system). The position of the vessel is monitored by GPS. It is connected to a station on shore, via GSM or satellite, for remote control and data transfer. The basic sensors used measure water temperature, conductivity, turbidity, oxygen, $\mathrm{pH}$ and chlorophyll- $a$-fluorescence.

The major routes of interest for COSYNA are the ones between Büsum and Helgoland, Cuxhaven and Immingham and Hamburg, Chatham, Immingham, Moos and Halden (Fig. 3). The sampling rate is $10 \mathrm{~s}$. The ship track is revisited with different time lags, depending on the distance to travel: Büsum-Helgoland, daily, Cuxhaven-Immingham, less than $36 \mathrm{~h}$, Hamburg-Cuxhaven-Chatham-ImminghamMoos-Halden about 8 day. Along some routes additional pa-

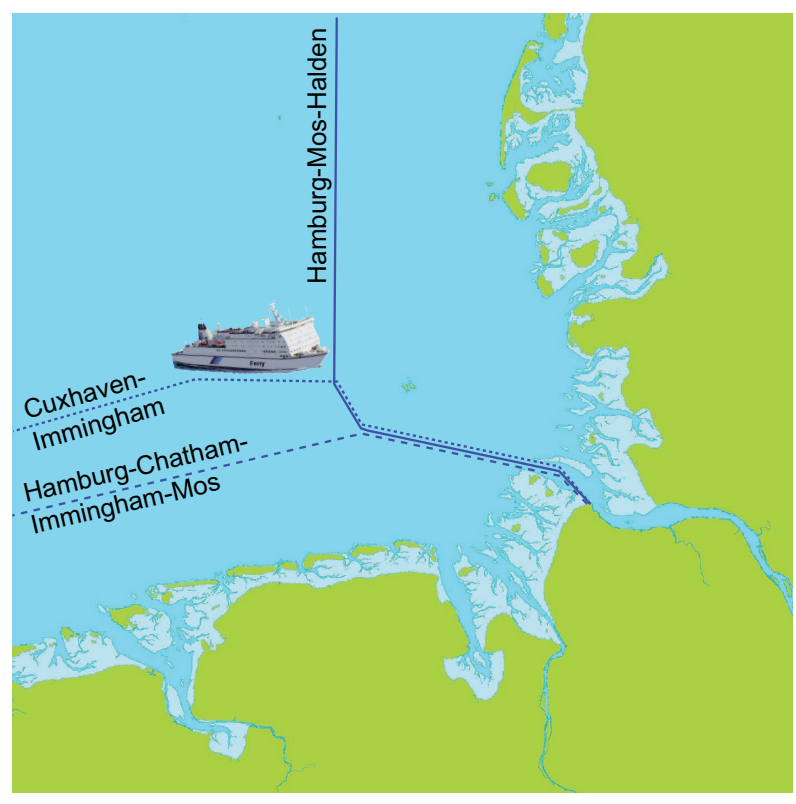

Fig. 3. FerryBox routes in the German Bight.

rameters are measured, e.g. algae classes and nutrients (ammonia, nitrite/nitrate, phosphate, silicate).

The route used here is the one from Cuxhaven to Immingham (see Fig. 3). This track has been analysed for the period 2007-2008 by Grayek et al. (2011), where the aliasing problem associated with the M2 tidal signal is discussed. It is demonstrated that reasonable estimation errors can be achieved with a linear interpolation method in combination with a filter operation. It has been demonstrated in this work that assimilation of FerryBox data leads to a qualitative improvement of the state estimates over large areas. In the present paper we will focus on a chosen operational period, which is March to July 2010. Because the track CuxhavenImmingham provides a regular stream of data with a revisiting time of $36 \mathrm{~h}$, which is much shorter than the revisiting time of the track Hamburg-Cuxhaven-Chatham-ImminghamMoos-Halden, we will use only the first one in this study and will use the same statistical technique as in the work by Grayek et al. (2011) for our exercise with a particular operational period.

Another important source of information for the present study is given by fixed stations in the German Bight (Fig. 4). Traditionally most of the fixed stations are operated by the German Federal Maritime and Hydrographic Agency (Bundesamt für Seeschifffahrt und Hydrographie, BSH). Their Marine Environmental Monitoring Network in the North Sea and Baltic Sea (MARNET) consists of six automatic oceanographic stations in the North Sea, five of which are currently operating (Fig. 4). Most stations measure temperature, salinity, oxygen, sea level, air temperature, wind direction, wind speed and air pressure. At some locations (e.g. FINO-1) 


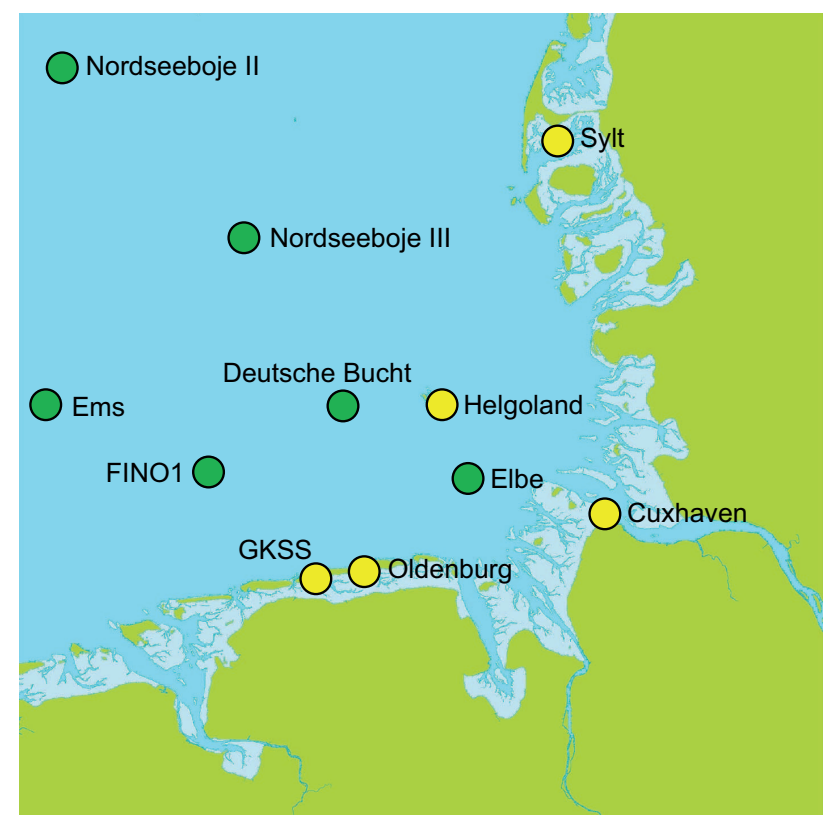

Fig. 4. Fixed stations in the German Bight. Green circles-locations of MARNET stations, yellow circles - coastal stations.

Acoustic Doppler Current Profilers (ADCP) are operating. We will be using in the following data from this network for validation purposes.

Apart from the sensors described above there are a couple of other instruments being used in the framework of COSYNA, which provide additional profile information, e.g., SCANFISH and gliders. These instruments are currently operated on a campaign basis and we will not discuss them in the context of data assimilation in this study.

\subsection{Remote sensing}

Since the pioneering work of Crombie (1955), who carried out first observations of the Doppler spectrum of sea echo by HF radars, remote sensing has become an important technology for observing coastal currents. Bragg scattering from the moving ocean surface by surface waves results in two discrete peaks in the Doppler spectrum (Stewart and Joy, 1974). The radar measures the radial component of the surface current by analyzing the additional Doppler shift caused by the underlying current field (Barrick et al., 1977). Applications resulted in developing the Coastal Ocean Dynamics Applications Radar (CODAR, Barrick et al., 1977; Paduan and Rosenfeld, 1996) and the Ocean Surface Current Radar (OSCR, Prandle, 1987; Shay et al., 1998). In the present paper we use data from the more recent Wellen Radar (WERA) system, which has been developed by Gurgel et al. (1999).

HF radars are capable of producing current vector maps of the coastal ocean over space scales up to hundreds of kilometres, and on temporal scales starting from tens of minutes.

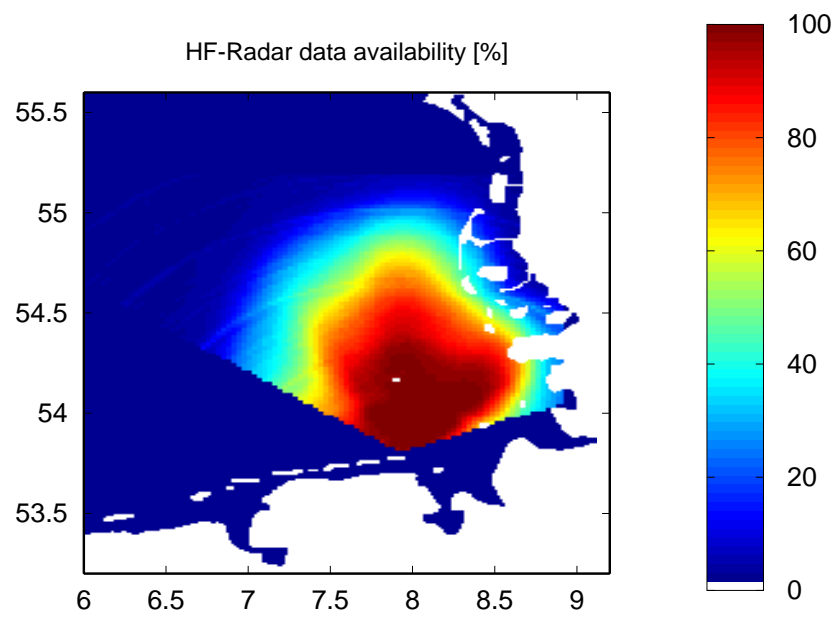

Fig. 5. HF radar array and data coverage. The colours illustrate the amount of valid data as percent of maximum number of records.

This unique resolution motivates the interest to use data from HF radars for a number of practical and theoretical applications (Emery et al., 2004; Barth et al., 2010, 2011). Typically, HF radar provides surface currents averaged over the top $0.5 \mathrm{~m}$ as hourly averages with a spatial resolution of 1 $2 \mathrm{~km}$ and accuracy of several $\mathrm{cm} \mathrm{s}^{-1}$. In many works the limitations of HF radars with respect of vertical resolution is complemented by ADCP observations (e.g., Paduan and Rosenfeld, 1996; Shay et al., 1998). As demonstrated by Shay et al. (2007) and Liu et al. (2010) mapping surface currents combined with ADCP data serves as a strong component of monitoring and prediction systems for coastal ocean. This dominating trend in developing coastal observatories is implemented in the framework of the integrated coastal observing system for the German Bight COSYNA. At the time when the present study was carried out HF-radar data from one station located at Wangerooge Island (Fig. 5) was available. Recently the observational system has been complemented by HF-radar measurements on Sylt and near Büsum (Fig. 1). These data are not used in the present study because the record is still too short. A disadvantage of using radial velocity is that available information is not sufficient to fully reconstruct surface velocity vectors. However, this challenge (Wahle and Stanev, 2011) motivated the development of a new algorithm presented in Sect. 4. Furthermore, using one radar only helps to isolate measurement errors arising from combining individual radars, a procedure that suffers from errors due to geometric dilution of precision (Chapman et al., 1997).

\subsection{Other data}

In the following we will only mention some other remote sensing data sources made available or used in the frame of COSYNA, which are not subject of the present 


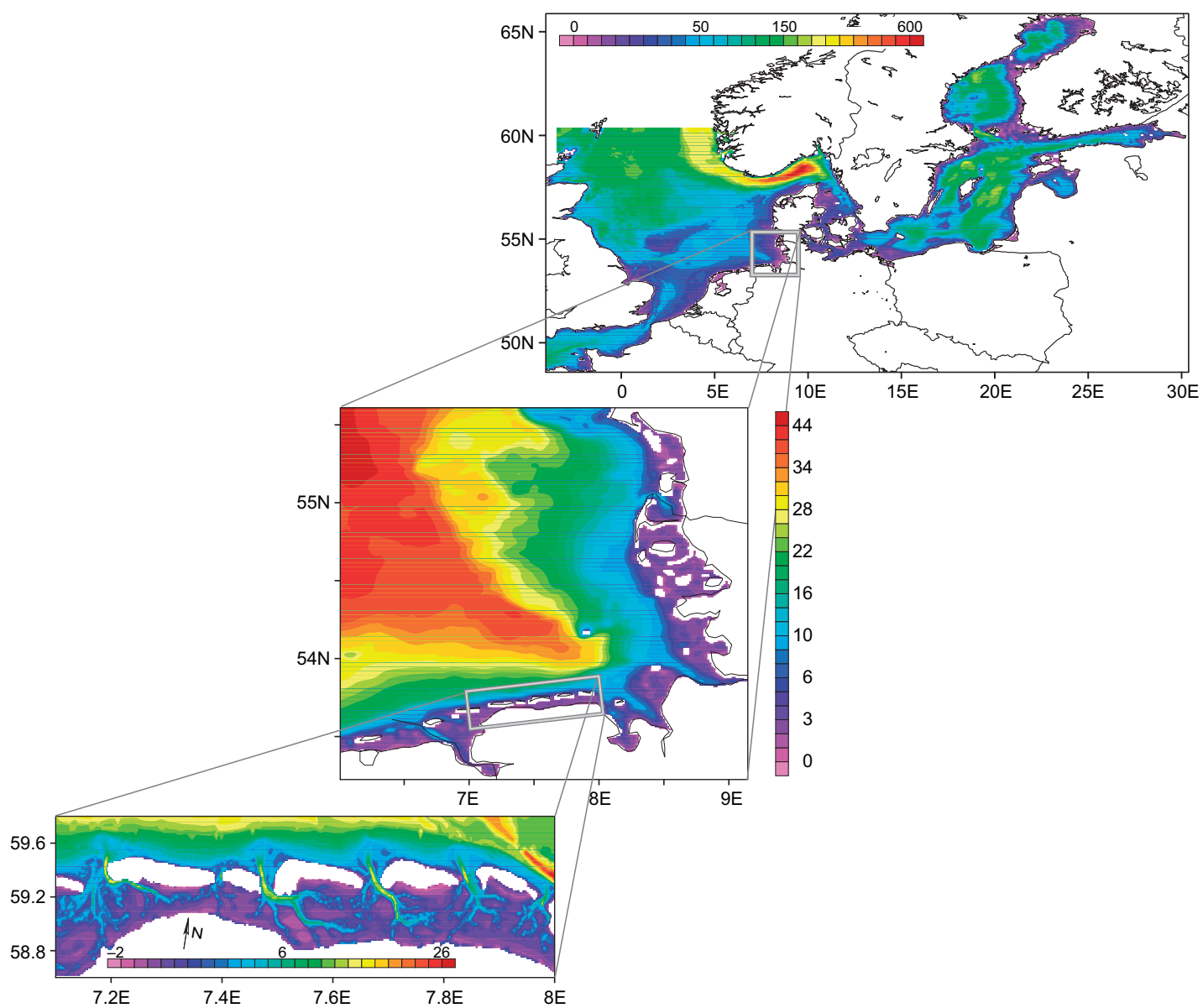

Fig. 6. Nested modelling system for the German Bight.

research. Synthetic aperture radars (SAR) use the dependence of small-scale roughness on the local winds, and practically relate the radar back scatter to wind parameters. With their resolution below $100 \mathrm{~m}$ SAR ensures valuable information about small scale characteristics of surface winds, waves and sea ice. The WISAR (Wind Retrieval from Synthetic Aperture Radar) system available in COSYNA is capable of handling SAR data from the satellites ERS-1, ERS-2, RADARSAT-1 and ENVISAT (Lehner et al., 1998; Horstmann and Koch, 2005; Koch, 2004).

Optical remote sensing enables monitoring phytoplankton and sediment concentrations over large areas. This is a very important development for the coastal ocean, which is characterized by large gradients of optical properties. The launch of the Medium Resolution Imaging Spectrometer (MERIS) on board of ENVISAT ensured a spatial resolution of $300 \mathrm{~m}$, a revisiting period of 1-2 days and 15 spectral bands (Schiller and Doerffer, 2005; Doerffer and Schiller, 2007). Recent applications described by Pleskachevski et al. (2011) motivate next activities to incorporate new types of remote sensing data in upgrading pre operational systems.

\section{Numerical models}

At present two modelling-platforms are used in COSYNA: the General Estuarine Transport Model (GETM, Burchard and Bolding, 2002) and the BSH operational model (Dick et al., 2001; Dick and Kleine, 2007), which operates in a backup mode. GETM is a primitive equation prognostic three-dimensional hydrodynamic model in spherical coordinates. The use of generalized vertical coordinates makes it suitable for shallow coastal regions under the influence of tidal currents. In this model the equations for the three velocity components, sea-surface height, temperature, salinity, as well as the equations for turbulent kinetic energy and the eddy dissipation rate due to viscosity are solved. A particular feature of GETM is its ability to adequately represent the dynamics in deep inlets and channels as well as on the tidal flats, the latter falling dry during part of the tidal period (Stanev et al., 2003).

In the following we will briefly present the nested modelling system based on GETM (Staneva et al., 2009). The nested-grid model consists of three model configurations: a coarse-resolution $\left(\Delta \phi=0.05^{\circ}, \Delta \lambda=0.08333^{\circ}\right.$, which 
is about $5 \mathrm{~km}$ ) North Sea-Baltic Sea outer model, a fineresolution $\left(\Delta \phi=0.00865^{\circ}, \Delta \lambda=0.01553^{\circ}\right.$, which is about $0.9 \mathrm{~km}$ ) inner model covering the German Bight and a very fine-resolution (about $200 \mathrm{~m}$ ) model for the Wadden Sea region resolving the barrier islands and the tidal flats. The bathymetric data for the different model configurations are prepared using the ETOPO-1 topography, together with observations made available by the BSH. Terrain following equidistant coordinates ( $\sigma$-coordinates) are used in the vertical, the water column is discretised into 21 non-intersecting layers.

The model system is forced by: (1) atmospheric fluxes estimated by the bulk formulation (Roussenov et al., 1995) using 1-hourly forecasts from the German Weather Service (DWD), (2) hourly river run-off data provided by the BSH operational model, and climatological data for the 30 most important rivers within the North Sea- Baltic Sea model area provided by the Swedish Meteorological and Hydrographical Institute (SMHI), and (3) time-varying lateral boundary conditions of sea surface elevations temperature and salinity. The sea surface elevation at the open boundary of the North Sea-Baltic Sea model is generated using tidal constituents obtained from the TOPEX/POSEIDON harmonic tide analysis. Temperature and salinity at the open boundary of the outer model are interpolated at each time step using the monthly mean climatological data of Janssen et al. (1999). The fresh-water fluxes from the main tributaries in the region are taken from the observations available from the Niedersächsischer Landesbetrieb für Wasserwirtschaft und Küstenschutz, Aurich, Germany.

Although the German Bight has been the subject to detailed national and international investigations (see e.g., Backhaus and Maier-Reimer, 1983; Soetje and Brockmann, 1983; Sündermann and Lenz, 1983; Droppert et al., 2000; Becker et al., 1999), neither the interaction between the North Sea and the German Bight, nor the exchange of water and properties between the Wadden Sea and the German Bight are quantitatively well known. The recent progress due to intercomparisons between observations and numerical modelling (Staneva et al., 2009) is currently extended in COSYNA activities towards more profound regional analyses (Port et al., 2011) and data assimilation (SchulzStellenfleth et al., 2011). More details on the characteristic circulation features can be found in the above mentioned papers. Here we will briefly summarise the overall performance of modelling system. In most of the German Bight, the residual circulation is cyclonic due to the dominant eastward wind forcing (Fig. 7a). The residual current (on a long-term, climatological time scale) is in the order of $5 \mathrm{~cm} \mathrm{~s}^{-1}$. The circulation is more intense off-shore and near the open boundaries of the German Bight.

The largest gradients of salinity are observed and simulated in the plumes of the rivers Elbe, Weser and Ems. Protrusions of diluted waters are better seen during low water both deep in the German Bight, as well as over the tidal
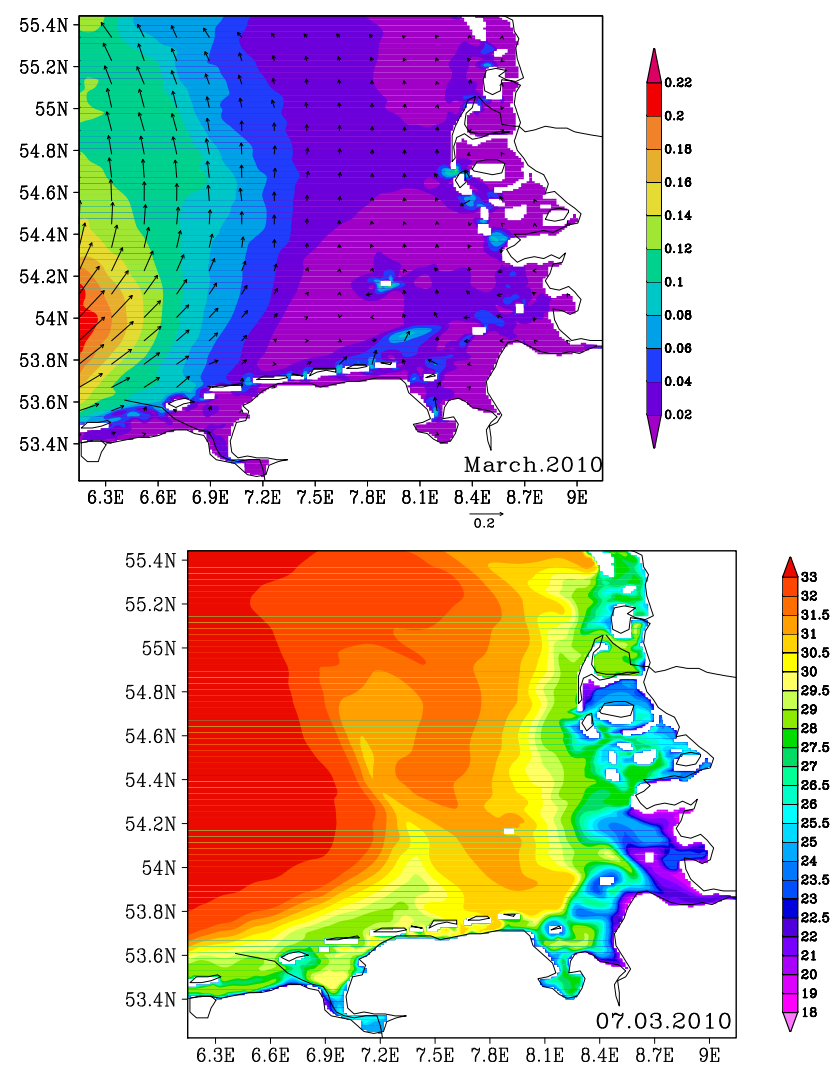

Fig. 7. Time-average of the vertically integrated circulation (in $\mathrm{ms}^{-1}$ ) in the German Bight during March 2010 (a) and surface salinity (in PSU) on 07/03/2010 (b).

flats. This is the case in Fig. 7b where water from the Ems River penetrates during periods of strong wind events eastwards into the tidal basins. More detailed analyses of simulations and data from the MERIS satellite (Staneva et al., 2009) demonstrate the similarity in the patterns of salinity and SPM (low salinity correlates well with high SPM concentration).

\section{Reconstruction of tidal currents based on radial component measured by HF-radar}

A number of studies demonstrated that valuable information about small scale hydrodynamic processes can be gathered by statistical analysis of HF radar measurements (e.g., Gough et al., 2010; Prandle, 1987; Port et al., 2011). Another promising application of $\mathrm{HF}$ radar data is the assimilation in numerical models in order to improve ocean forecasts. The implementation of an assimilation system for such measurements is however not a trivial task. For example one has to deal with irregular data gaps and inhomogeneous observation errors (e.g., Kim et al., 2007; Ivanov and Melnichenko, 2005). Furthermore the treatment of the boundary forcing and the information transfer into the subsurface layers are 


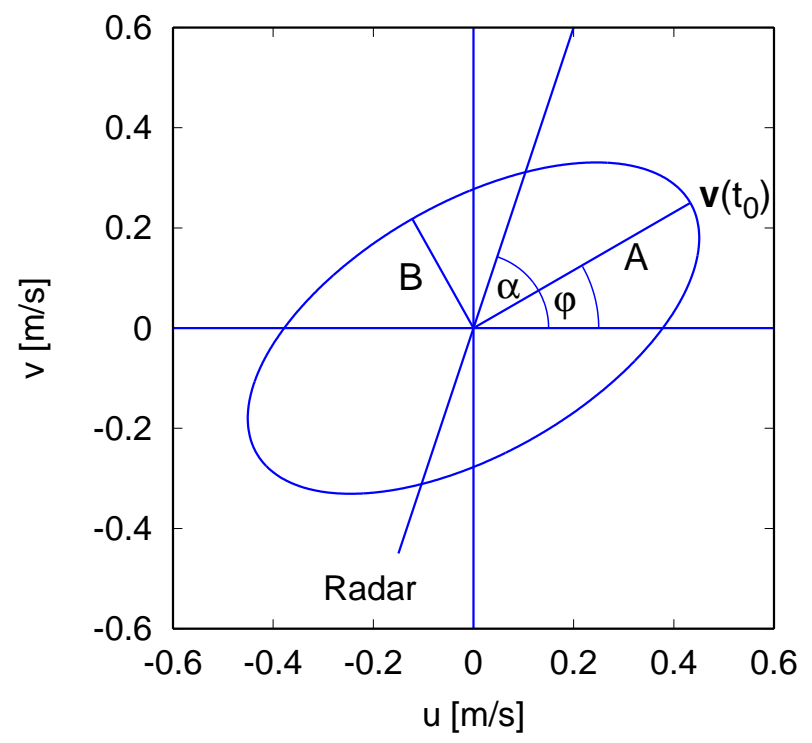

Fig. 8. Schematic representation of observational set up along with some of the important model parameters

demanding problems. The assimilation techniques proposed in literature include optimal interpolation (e.g., Breivik and Saetra, 2001), more sophisticated statistical approaches (e.g., Oke et al., 2002; Paduan and Shulman, 2004; Barth et al., 2008, 2010), variational techniques (e.g., Sentchev et al., 2006; Yaremchuk and Sentchev, 2009; Scott et al., 2000; Kurapov et al., 2003) and adhoc methods (e.g., Lewis et al., 1998).

In the following a simple approach is presented to combine radial surface current measurements acquired by a single HF radar station with a priori information from a hydrodynamic model. The method provides estimates of tidal ellipses parameters and is based on a maximum a posteriori approach. As a basis for the solution of the inversion problem the tidal ellipses parameters of the 2-D current field are related to the M2 phase and magnitude of the radial current component measured by the radar. Using complex notation with the imaginary axis pointing in the meridional direction and the real axis pointing in the zonal direction, the current vector $v$ rotating around a tidal ellipse can be written as

$$
\boldsymbol{v}(t)=\left(A \cos \left(\omega_{2}\left(t-t_{0}\right)\right)+i B \sin \left(\omega_{2}\left(t-t_{0}\right)\right) \exp (i \varphi)\right.
$$

with inclination $\varphi$ and major and minor axis $A$ and $B$, respectively (Fig. 8). Furthermore $\omega_{2}$ denotes the M2 frequency. The strongest currents with magnitude $A$ occur at time $t_{0}$ in the direction $\varphi$.

The radial component obtained by an HF radar station with look direction $\alpha$ is then given as

$$
\begin{aligned}
R(t) & =\mathrm{RE}(\boldsymbol{v} \exp (-i \alpha)) \\
& =D \cos \left(\omega_{2}\left(t-t_{1}\right)\right),
\end{aligned}
$$

where RE denotes the real part and $D$ is defined as

$D=\sqrt{A^{2} \cos ^{2}(\delta)+B^{2} \sin ^{2}(\delta)}$

with

$\delta=\varphi-\alpha$

$t_{1}=t_{0}-\beta / \omega_{2}$

and the M2 phase difference $\beta$ between the maximum current magnitude and the maximum radial component given by

$\beta=\arctan (B \sin (\delta), A \cos (\delta))$.

The strongest radial components of magnitude $D$ occur at time $t_{1}$. Lets assume we have a measurement of the M2 phase and magnitude $t_{1}^{\mathrm{HF}}, D^{\mathrm{HF}}$ from the $\mathrm{HF}$ radar and the parameters $A^{\mathrm{m}}, B^{\mathrm{m}}, t_{0}^{\mathrm{m}}, \varphi^{\mathrm{m}}$ are provided by the model. If an estimate of the model errors and the measurement errors is available we can take a standard maximum a posteriori approach (e.g., Bennett, 1992) to combine the measurement and the prior information in an optimal way. This approach results in a cost function of the form

$$
\begin{aligned}
& J\left(A, B, t_{0}, \varphi\right) \\
& =w_{A}\left(A-A^{\mathrm{m}}\right)^{2}+w_{B}\left(B-B^{\mathrm{m}}\right)^{2}+w_{t_{0}}\left(t_{0}-t_{0}^{\mathrm{m}}\right)^{2} \\
& +w_{\varphi}\left(\varphi-\varphi^{\mathrm{m}}\right)^{2}+w_{t_{1}}\left(t_{0}-\beta / \omega_{2}-t_{1}\right)^{2} \\
& +w_{D}\left(\sqrt{A^{2} \cos ^{2}(\delta)+B^{2} \sin ^{2}(\delta)}-D\right)^{2} .
\end{aligned}
$$

Here, the weighting coefficients $w_{A}, w_{B}, w_{t_{0}}, w_{\varphi}, w_{t_{1}}$ and $w_{D}$ can be interpreted as the expected reciprocal squared errors for the different components. To simplify the following expressions we define the cost function in terms of $\delta$ instead of $\varphi$.

One then gets

$$
\begin{aligned}
& J\left(A, B, t_{0}, \delta\right) \\
& =w_{A}\left(A-A^{\mathrm{m}}\right)^{2}+w_{B}\left(B-B^{\mathrm{m}}\right)^{2}+w_{t_{0}}\left(t_{0}-t_{0}^{\mathrm{m}}\right)^{2} \\
& +w_{\delta}\left(\delta-\delta^{\mathrm{m}}\right)^{2}+w_{t_{1}} C_{t_{1}}^{2}+w_{D} C_{D}^{2}
\end{aligned}
$$

with

$$
\begin{aligned}
& C_{t_{1}}=t_{0}-\omega_{2}^{-1} \arctan (B \sin (\delta), A \cos (\delta))-t_{1}^{\mathrm{HF}} \\
& C_{D}=\sqrt{A^{2} \cos ^{2}(\delta)+B^{2} \sin ^{2}(\delta)}-D^{\mathrm{HF}}
\end{aligned}
$$

The cost function and its derivative are nonlinear and a solution for the minimum was therefore seeked using a numerical iteration scheme. In the first step the gradient is computed analytically resulting in

$$
\begin{aligned}
& \frac{\partial J}{\partial A}=2 w_{A}\left(A-A^{\mathrm{m}}\right)+2 w_{t_{1}} C_{t_{1}} \frac{\partial C_{t_{1}}}{\partial A}+2 w_{D} C_{D} \frac{\partial C_{D}}{\partial A} \\
& \frac{\partial J}{\partial B}=2 w_{B}\left(B-B^{\mathrm{m}}\right)+2 w_{t_{1}} C_{t_{1}} \frac{\partial C_{t_{1}}}{\partial B}+2 w_{D} C_{D} \frac{\partial C_{D}}{\partial B} \\
& \frac{\partial J}{\partial t_{0}}=2 w_{t_{0}}\left(t_{0}-t_{0}^{\mathrm{m}}\right)+2 w_{t_{1}} C_{t_{1}} \\
& \frac{\partial J}{\partial \delta}=2 w_{\delta}\left(\delta-\delta^{\mathrm{m}}\right)+2 w_{t_{1}} C_{t_{1}} \frac{\partial C_{t_{1}}}{\partial \delta}+2 w_{D} C_{D} \frac{\partial C_{D}}{\partial \delta}
\end{aligned}
$$


Table 1. Weighting parameters used for the cost function Eq. (9).

\begin{tabular}{cccccc}
\hline$w_{A}$ & $w_{B}$ & $w_{t_{0}}$ & $w_{\delta}$ & $w_{t_{1}}$ & $w_{D}$ \\
\hline $0.05^{-2} \mathrm{~m}^{-2} \mathrm{~s}^{2}$ & $0.1^{-2} \mathrm{~m}^{-2} \mathrm{~s}^{2}$ & $900^{-2} \mathrm{~s}^{-2}$ & $(10 \pi / 180)^{-2}$ & $900^{-2} \mathrm{~s}^{-2}$ & $0.05^{-2} \mathrm{~m}^{-2} \mathrm{~s}^{2}$ \\
\hline
\end{tabular}

where the following definitions were used:

$$
\begin{aligned}
& \frac{\partial C_{t_{1}}}{\partial A}=\frac{1}{\omega_{2}} \frac{B \sin \delta \cos \delta}{Z} \\
& \frac{\partial C_{t_{1}}}{\partial B}=-\frac{1}{\omega_{2}} \frac{A \cos \delta \sin \delta}{Z} \\
& \frac{\partial C_{t_{1}}}{\partial \delta}=-\frac{1}{\omega_{2}} \frac{A B}{Z} \\
& \frac{\partial C_{D}}{\partial A}=Z^{-1 / 2} A \cos ^{2} \delta \\
& \frac{\partial C_{D}}{\partial B}=Z^{-1 / 2} B \sin ^{2} \delta \\
& \frac{\partial C_{D}}{\partial \delta}=Z^{-1 / 2} \sin \delta \cos \delta\left(B^{2}-A^{2}\right) \\
& Z=A^{2} \cos ^{2} \delta+B^{2} \sin ^{2} \delta
\end{aligned}
$$

To compute the minimum of the cost function a Newton method is applied to find zero crossings of the gradient. The Jacobian matrix is estimated using forward differences with a step size of $h=10^{-4}$. If the Newton method does not provide a descent direction the steepest descent direction (i.e., $-\nabla J)$ is used with a step size control to ensure a decrease of the cost function. The ellipses parameters from the original model run are used as initial values for the iteration. The Newton iteration is terminated if the gradient norm is below $10^{-5}$. The weighting parameters in the cost function were chosen according to Table 1.

The method was applied to data acquired by the HF radar station located at Wangerooge. An example of radial surface current components measured by this station is shown in Fig. 9 (top). The corresponding 2-D surface current field obtained with the numerical model is given in Fig. 9 (bottom). The M2 phase and magnitude was estimated from data taken over a period of $12 \mathrm{~h}$ on 1 November 2009 using a least squares technique. Only points with at least $50 \%$ data availability were considered for the estimation.

The a priori information was taken from the primitive equation model described in Sect. 3. The tidal ellipses parameters were estimated for the same period of $12 \mathrm{~h}$ on 1 November 2009 already used for the HF radar.

The inversion for one particular point west of the island Helgoland is shown in the bottom part of Fig. 10. In this case the iteration terminated after 6 iteration steps. The cost function value decreased from an initial value of 4.36 to 1.33. A comparison of the ellipses parameters from the model and the final retrieval is given in Table 2. The main differences of the retrieval and the original model is an anticlockwise

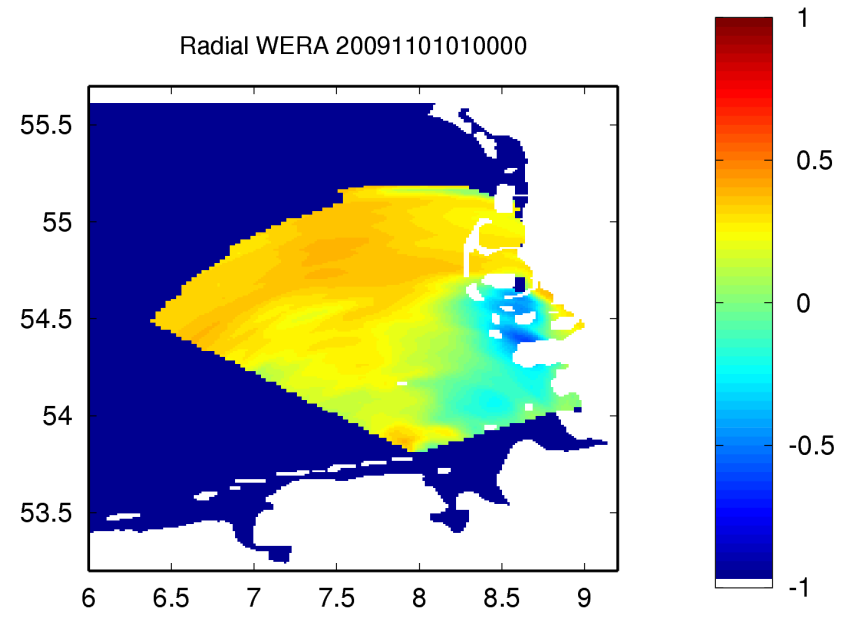

GETM surface curren 20091101010000

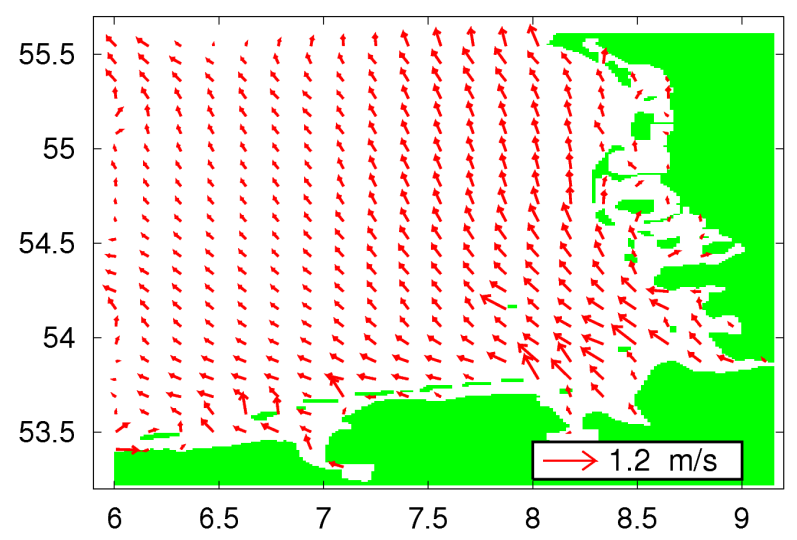

Fig. 9. Radial velocities measured by the HF radar station at the island Wangerooge on 1 November 2009 at 01:00 UTC (top). Corresponding $2 \mathrm{D}$ surface current field obtained with the numerical model (bottom).

Table 2. Tidal ellipses parameters derived from the numerical model and the respective analysis using HF radar data from a single antenna station.

\begin{tabular}{lcccc}
\hline & $A$ & $B$ & $t_{0}$ & $\varphi$ \\
\hline Model & $0.38 \mathrm{~ms}^{-1}$ & $0.01 \mathrm{~ms}^{-1}$ & $7.56 \mathrm{~h}$ & $-23.8^{\circ}$ \\
Retrieval & $0.36 \mathrm{~ms}^{-1}$ & $0.09 \mathrm{~ms}^{-1}$ & $7.47 \mathrm{~h}$ & $-18.1^{\circ}$ \\
\hline
\end{tabular}



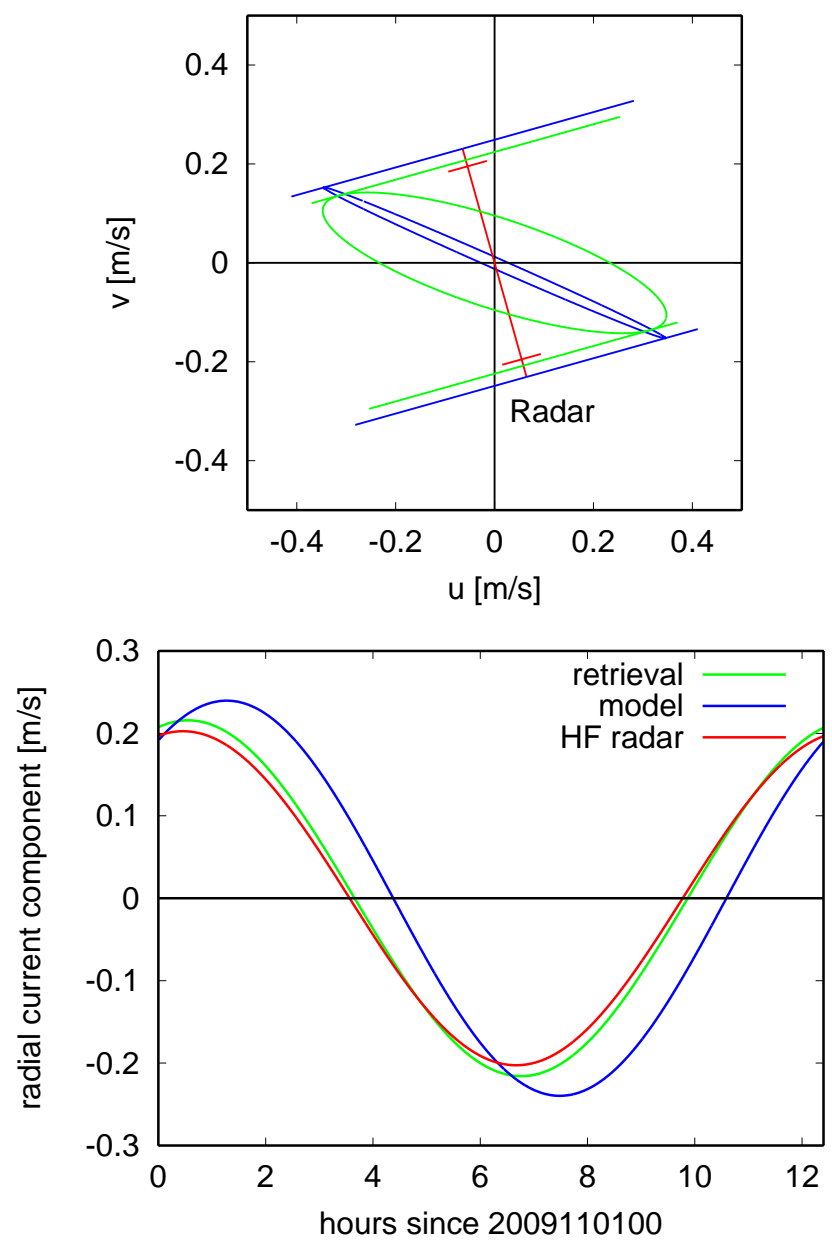

Fig. 10. Illustration of the tidal ellipses parameter retrieval method. (top) The blue ellipses is derived from the numerical model for the position $7.75^{\circ}$ E $54.26^{\circ} \mathrm{N}$ (west of Helgoland) on 1 November 2009. The red lines indicate the amplitude of the radial component measured by the radar at Wangerooge. The green ellipses is obtained by combination of the HF radar data and model information using models for both forecast and measurement errors. (bottom) Time series of the radial M2 current components with the same color coding as in the upper plot.

rotation of the major axis and an increase of the ellipticity $(=B / A)$. The minor axis $B$ is positive in all cases indicating a anticlockwise rotation of the current vector (see also Fig. 10). Table 3 shows the resulting improvement in the agreement of the parameters observable by the radar. The original model data showed a time shift of $0.81 \mathrm{~h}$ of the radial velocities with respect to the observations with the model lagging behind the observation. The remaining time shift between the retrieved and the observed radial velocities is about 6 min. As one can see in Fig. 10 this improvement is in particular achieved by the modification of the ellipticity.

A comparison of analysed current velocity vectors with the original model results is shown in Fig. 11 for 1 November, 00:00 UTC (top) and half a tidal cycle later (bottom). One
Table 3. M2 amplitude and the time of maximum strength of the radial current component as observed from the Wangerooge station as well as simulated from the original model results and the final analysis.

\begin{tabular}{lcc}
\hline & $D$ & $t_{1}$ \\
\hline HF radar & $0.20 \mathrm{~ms}^{-1}$ & $0.46 \mathrm{~h}$ \\
Model & $0.24 \mathrm{~ms}^{-1}$ & $1.27 \mathrm{~h}$ \\
Retrieval & $0.22 \mathrm{~ms}^{-1}$ & $0.55 \mathrm{~h}$ \\
\hline
\end{tabular}

can see that the differences in both magnitude and direction are moderate for the whole domain indicating an overall good consistency of the numerical model with the HF radar measurements. The approach gives a first hint in which direction the measurements are "pulling" the model in the assimilation. In this sense the method is a robust and helpful first step towards the implementation of a more sophisticated assimilation system. However, due to the point by point inversion there are no constraints concerning differential properties of the retrieved current fields and hence unrealistic vorticity or divergence values could be an issue. The inclusion of regularisations for spatial correlations requires a linearisation of the problem, which can be done in a quite straightforward way not discussed here any further. Figure 12 shows a comparison of the radial velocity amplitude $D$ for the free run (top), the radar observations (centre), and the analysis (bottom). One can see that the analysis is in a significantly better agreement with the observations than the free run. We also see that the observations are relatively smooth with correlation lengths comparable to the free run. The proposed point by point analysis thus seems to be acceptable as a first step.

If two or more HF radar stations are available, estimates of the complete 2-D surface current field are provided. The extension of the presented approach to this scenario is straightforward. However, as the dynamical consistency of the analysed current fields is an important issue in the COSYNA project, more sophisticated assimilation methods will be applied once data from a second and third radar station in Büsum and Sylt will be available.

\section{Assimilation of FerryBox data}

The impact of assimilating FerryBox data into numerical models has been studied for the Aegean Sea (Korres et al., 2009), where a positive impact on the predicted variables within the Southern Aegean Sea has been demonstrated. Nevertheless, we consider that the use of this relatively new type of oceanographic information in operational practice is still limited. In particular, no record of assimilation of such kind of data for the North Sea exists at present. 
Hours since Nov, 1, 2009 00:00 UTC: 0.3

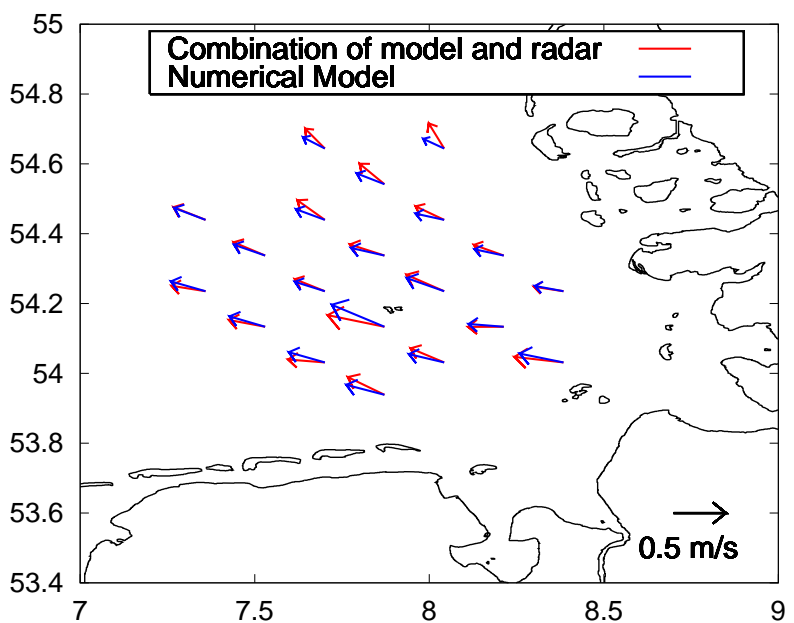

Hours since Nov, 1, 2009 00:00 UTC: 6.2

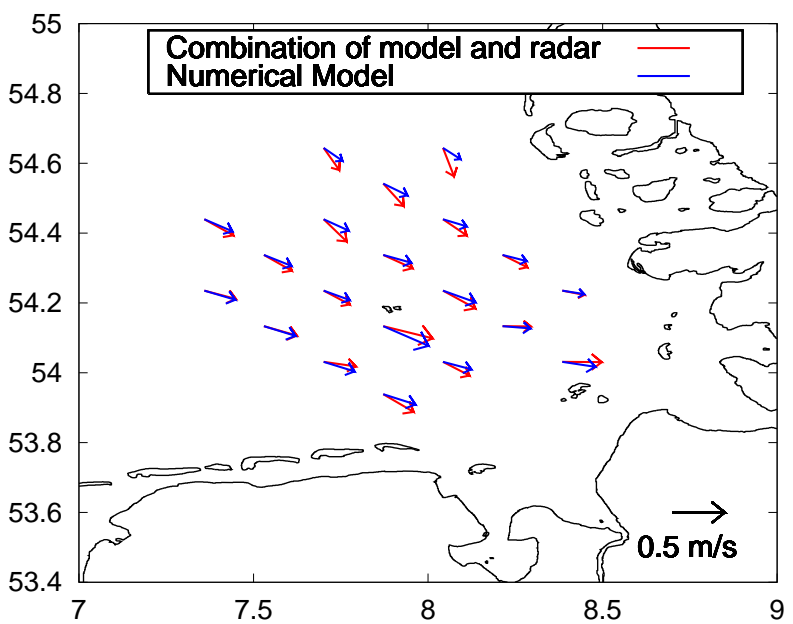

Fig. 11. Comparison of original current vectors (blue) from the numerical model with analysed current vectors obtained by combination with radial components measured by the HF radar station at Wangerooge (red) for 1 November 2009, 00:00 UTC (top) and half a tidal cycle later (bottom).

Assimilation of FerryBox data in the present study is based on an optimal interpolation approach using Kalman filter and a stationary background covariance matrices derived from a preliminary model run without data assimilation for the same period, which we call henceforth the "Free Run". The general concept of the assimilation is described in the following.

Let us denote the global (index "GL") state vector of dimension $m$ by $x$ and the FerryBox (index "FB") measurement vector of dimension $n$ by $y$. $x$ contains either SSS or SST at the individual position of the model area and $y$ either SSS or SST along the FerryBox track. In the following we assume that both the measurements and the state variables have the mean removed.
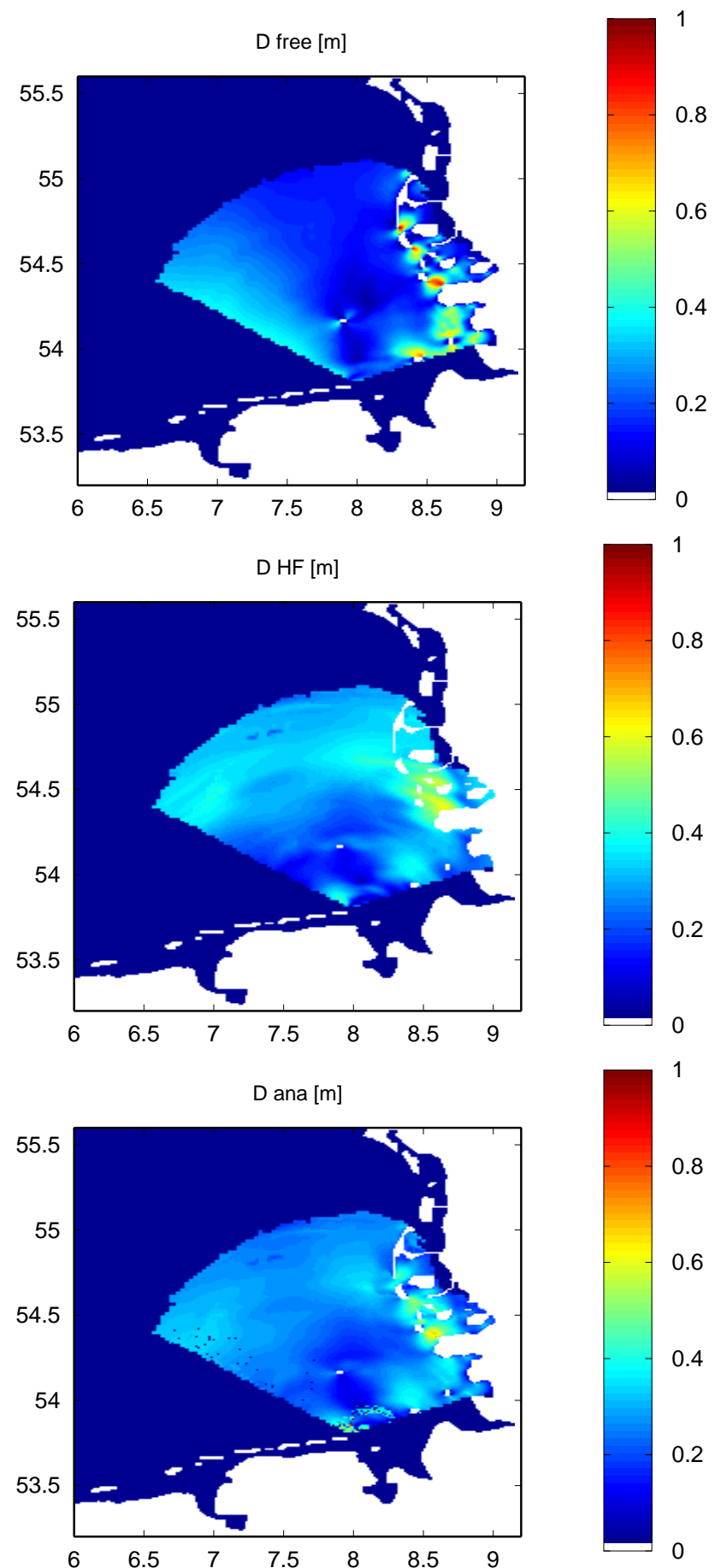

Fig. 12. Radial velocity amplitude $D$ for the free run (top), the radar observations (centre), and the analysis (bottom) estimated for 1 November 2009.

We make use of the improved model state estimates $x^{f}\left(t_{i}\right)$ for the current time step $t_{i}$ by taking them as forecast and update them according to the found misfit to the observations from the FerryBox $y^{o}\left(t_{i}\right)$. Furthermore, we additionally reconstruct and update the temperature and salinity value of 
the whole water column based on simulated profile characteristics in order to enhance the influence of the assimilation. Because the variables, which are observed by the FerryBox (SST and SSS), only constitute a small part of the model state and, on the other hand, have a very close connection to the atmospheric forcing the major part of the updated characteristics would be lost otherwise very rapidly when restarting the model. The sequence of operations is demonstrated in Fig. 13.

An update of the forecasted field is performed every $24 \mathrm{~h}$ at 12:00 o'clock model time where we stop the model, extract the forecast field and restart the model from the updated global state. In the standard Kalman filter approach the reconstruction of the global state $x^{a}\left(t_{i}\right)$ is given by:

$x^{a}\left(t_{i}\right)=\mathrm{EOF}^{\mathrm{GL}} A\left(y^{o}\left(t_{i}\right)-y^{f}\left(t_{i}\right)\right)+x^{f}\left(t_{i}\right) \quad$ with

$y^{f}\left(t_{i}\right)=H x^{f}\left(t_{i}\right)$ and

$x^{f}\left(t_{i}\right)=M x^{a}\left(t_{i-1}\right)$,

where $M$ is the model operator describing the evolution of the model state according to the model physics and the forcing fields. To reduce the dimension of the state vector an Empirical Orthogonal Functions (EOF) analysis is applied. The original state vector components are thus replaced by the vector of Principal Components (PCs) associated with the EOFs. The analysis Eq. (23) refers to this transformed state space. The matrix EOF ${ }^{\mathrm{GL}}$ contains the first 31 dominating EOFs of the global state and $A$ is the re-construction matrix, which is the well known Kalman gain matrix for the corresponding PCs (Schulz-Stellenfleth and Stanev, 2010).

The presented OI assimilation scheme for the FerryBox data uses a distance-dependent localisation, which filters out long-range correlations in the background covariance matrix P. A Gaussian function, which depends on the Euclidean distance between the updated point in state space and the observations is used as a filter. The update of the forecasted field is done by introducing a localised version of the reconstruction matrix A for each individual position $j_{u}=1, \ldots, m$ according to

$\mathbf{A}^{j_{u}}=\mathbf{P} H^{\mathrm{T}}\left(H P H^{\mathrm{T}}+\left(\mathbf{W}^{j_{u}}\right)^{-1} \mathbf{R}\left(\mathbf{W}^{j_{u}}\right)^{-1}\right)^{-1}$,

where $\mathbf{R}$ is the observation error covariance matrix and $\mathbf{W}^{j_{u}}$ is a diagonal matrix containing the weighting factors of the observations, which correspond to the updated position $j_{u}$.

Measurement errors of FerryBox systems are negligible in comparison to methodological errors of FerryBox sampling and the observation errors $R$ in Eq. (26) are thus dominated by the latter. Due to the given revisit time of the Ferry, the tidal variation of SST and SSS are not resolvable from FerryBox measurements and, therefore, are not well considered by the assimilation scheme. In order to minimise its influence on the reconstruction we estimate the mean daily amplitude of the tidal variation of SST and SSS from the free run and use it as an approximation for $R$. For the experiment in the present paper the measurement error covariance matrix

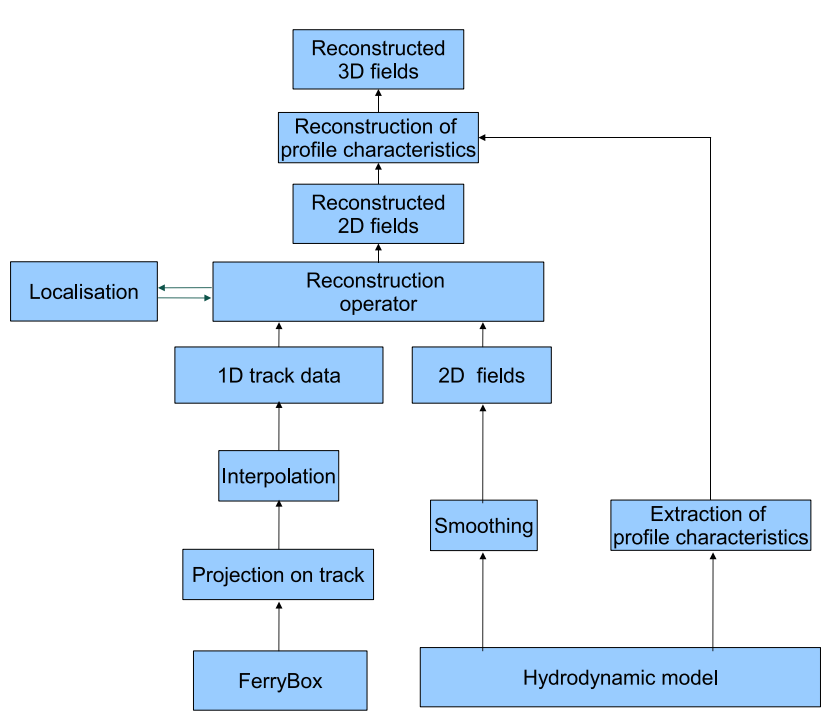

Fig. 13. Data flow diagram and operations used for reconstruction of 3-D temperature and salinity fields from FerryBox measurements.

$R$ is assumed to be diagonal with an error standard deviation of $0.5^{\circ} \mathrm{C}$ for SST and 0.25 for SSS. An investigation of the impact of not considered tidal signals together with a more detailed description of the assimilation approach is given in Grayek et al. (2011).

In this study we assimilate SST and SSS from the FerryBox system for the period from 1 March 2010 to $8 \mathrm{Au}$ gust 2010. We perform an assimilation step every $24 \mathrm{~h}$ at 12:00 UTC (Fig. 13). The interpolation and reconstruction of the FerryBox measurements is discussed in detail in Grayek et al. (2011). As mentioned above, we use a preliminary model run (the free model run), to calculate the background covariance matrices. In the following experiments covariance matrices are used as described above. We refer to the experiment in which the FerryBox data are assimilated as to the data assimilation (DA) experiment.

Comparisons of simulations versus independent in-situ observations from the MARNET Deutsche Bucht Data station are presented in Fig. 14 for March and July 2010. Note that the MARNET Station data shown here are at $6 \mathrm{~m}$ depth because no surface data were available for the study period. Another source of validation data is provided by the Operational Sea Surface Temperature and Sea Ice Analysis (OSTIA) data. The OSTIA system produces a high resolution analysis of the current SST for the global ocean using satellite data provided by the GHRSST (The Group for HighResolution SST) project, together with in-situ observations to determine the sea surface temperature (Donlon et al., 2009). The analysis is performed using a variant of optimal interpolation and is provided daily at a resolution of $1 / 20^{\circ}(5 \mathrm{~km})$. The OSTIA data package includes also error estimates for the given SST values. The claimed mean error for the region and period investigated in this paper is $1.2^{\circ} \mathrm{C}$. 
(a)

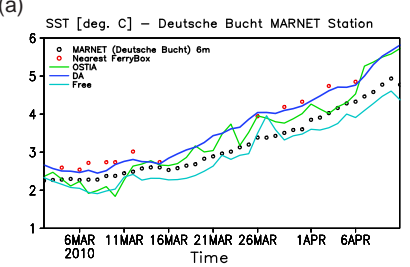

(c)

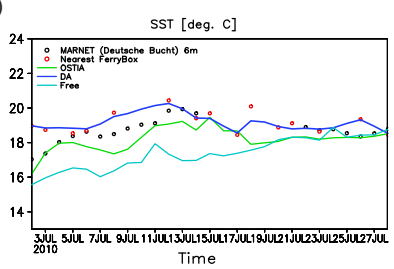

(b)

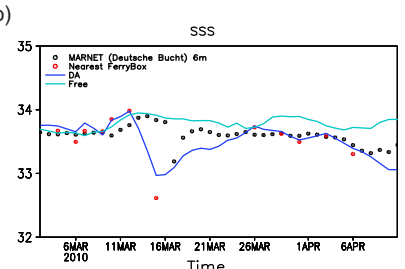

(1)

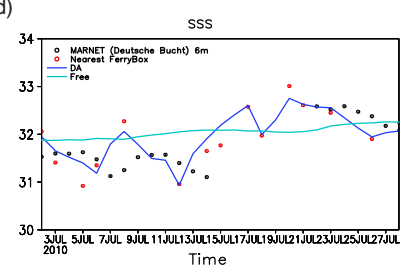

Fig. 14. Comparison of simulated SST (a, c) and SSS (b, d) from the Free Run and DA Run analysis fields against MARNET observations at Deutsche Bucht Station, located at $54.17^{\circ} \mathrm{N}$, and $7.45^{\circ} \mathrm{S}$.

The Free Run SST at the Deutsche Bucht station is colder than both the MARNET observations and the OSTIA SST. Data assimilation significantly improves the SST increasing its values to the one of the ship observations. The OSTIA and FerryBox SST are warmer than the MARNET Deutsche Buch station at $6 \mathrm{~m}$ for the whole study period. Regarding SST values we find a misfit between the free run and the observations at Deutsche Bucht MARNET Station of about $0.5^{\circ} \mathrm{C}$ in March 2010 (Fig. 14a) and a misfit of $1-2^{\circ} \mathrm{C}$ in July 2010 (Fig. 14c), which are corrected almost completely in the assimilation run.

For the salinity values at the Deutsche Bucht station we also find significant improvements during both periods (March 2010, Fig. 14b and July 2010, Fig. 14d). Data assimilation triggers higher sea surface salinity variations, observed in both FerryBox and also in the independent MARNET measurements (e.g. lowering of the salinity on 16 March and 11 July). The time variability of the SSS from the Free Run is smoother than from the DA run and observations mostly because with one kilometer resolution used here the model can not enough resolve all important scales in the frontal dynamics.

The performance of the SST assimilation is analysed by comparing the RMS differences between the model simulated SST with independent observations from OSTIA for March 2010 (Fig. 15). The average of the error range of the OSTIA data as contained in the standard product for the same period is given as well (Fig. 15a). The RMSE values of the Free Run versus OSTIA (Fig. 15b) demonstrate that in the most of the offshore area of the German Bight the values the RMSE are relatively low (lower than $0.5^{\circ} \mathrm{C}$ ). Thus, the German Bight Free Run model is capable of simulating the surface temperature reasonably well. The RMSE values in the coastal areas, as well as north of the East Frisian Islands are higher than the OSTIA error range, due to the coarse resolution given by the OSTIA data. The improvement of the

(a)
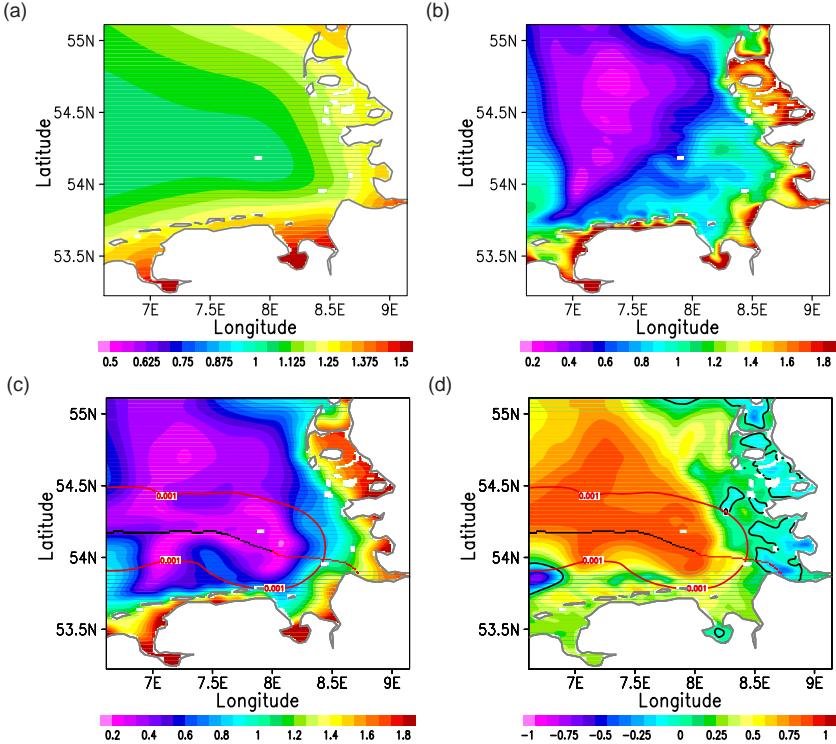

Fig. 15. Error range of OSTIA SST for March 2009 (a). (b) and (c) show temporal mean RMSE for the March 2009 using OSTIA SST and SST from the Free Run and DA Run analysis fields, respectively. (d) shows the Skill of DA Run, which corresponds to (b) and (c). The red line in c) and d) indicates the area around the ferry track in which the value of the Gaussian decay used in the localisation lies above $10^{-3}$. Beyond this line the influence of the data assimilation can be neglected.

DA run with respect to the free run taking OSTIA data as a reference is shown in Fig. 15d. In order to assess the improvement we calculated the skill of the DA run according to

Skill $=\frac{\mathrm{RMSE}^{r}-\mathrm{RMSE}^{\mathrm{DA}}}{\mathrm{RMSE}^{r}}=1-\frac{\mathrm{RMSE}^{\mathrm{DA}}}{\mathrm{RMSE}^{r}}$,

where RMSE ${ }^{\mathrm{DA}}$ stands for the RMSE calculated from the output of the data assimilation run and $\mathrm{RMSE}^{r}$ for the RMSE calculated from the Free Run.

It is evident that the assimilation is capable to improve the SST, mainly nearby the ship route. The areas with a negative impact of DA are mostly due to an inadequate response of the model to the analysis rather than the analysis itself, which is rather localised around the ship track. Detailed analysis of the model skill proved that the global state estimate is considerably improved using the proposed OI method.

To our knowledge, there are no global scale observations of SSS for the investigated region, therefore, analyses of SSS are not included here. 


\section{Conclusions}

The overall characteristics of the observational system in the German Bight, which is part of the COSYNA initiative are described in the present paper. Because the operational mode of COSYNA will be maintained over a long-term period it is of utmost importance to critically establish usefulness of different observational platforms in improving state estimates and quality of forecasts. There is still some way to go before assessing which measurements will provide the greatest rewards for data assimilation and for which processes and time scales the benefits are largest. The two examples of shortening the distance between observations and numerical simulations presented here focused on surface velocity and thermohaline characteristics of coastal ocean describe one useful step in this direction.

A new and relatively simple point-by-point approach combining radial surface current measurements from a single HF radar with a priori information from a hydrodynamic model is developed. The method relates tidal ellipses parameters of the 2-D current field and the M2 phase and magnitude of the radials measured by the radar. The robustness of the method is ensured by the optimal combination of the measurement and the prior information from the model, the minimum of the cost function is computed using a Newton iteration method. The analysed differences in magnitude and direction of surface currents are moderate for the whole domain indicating an overall good consistency of the numerical model with the HF radar measurements. Furthermore, the method proposed reveals in which direction and how much the measurements could pull the model in the assimilation. It is concluded that although the proposed method can not substitute data assimilation it presents (1) a robust and helpful first step towards the implementation of a more sophisticated assimilation system, (2) provides a clear basis for identification of inconsistencies between two data sources, (3) reveals that even using incomplete information could substantially benefit state estimates in the coastal ocean.

The second example addressed assimilation of FerryBox data based on an optimal interpolation approach using Kalman filter and a stationary background covariance matrix derived from a preliminary model run, which was validated against remote sensing. The method used assumes a distance-dependent localisation, which filters out longrange correlations in the background covariance matrix. OSTIA and MARNET data are used for skill estimations. The model is capable to simulate the surface temperature reasonably well, in particular in the offshore area of the German Bight. It was demonstrated that data assimilation significantly improves the performance of the model with respect to both SST and SSS. Although this improvement is mostly around the Ferry track, it is demonstrated that in general the skill is good over larger areas covered by the model solution.

Above results are relevant to expected advances in the development of model-assisted new measurement strategies for adaptive sampling by using a combination of various in situ observing platforms, e.g., buoys, piles, ferryboxes, gliders and AUVs. One methodological step in this direction has been already illustrated by Schulz-Stellenfleth and Stanev (2010). New platforms-of-opportunities like North Sea ferries and offshore wind farms would enable a cost effective operation of COSYNA state estimates, monitoring and forecasting. Thus, the maritime exploitation like offshore wind energy conversion will not only be an object of research, but also a fundamental prerequisite for long-term observations. It is not only expected that the information produced by COSYNA will significantly contribute to answering specific science and management questions such as the ecosystem response to ocean warming, the interaction of wave climate and sediment dynamics, the matter exchange between ocean and atmosphere in the coastal zone, the sensitivity of coastal morphology to transport of sediments and sea level rise, but that this initiative will provide a number of products such as regularly produced maps, states estimates and forecasts, supporting monitoring strategies, management and decision making (one initial step in this direction is documented recently by Schulz-Stellenfleth et al., 2011).

Acknowledgements. This research has been initiated in the frame of the ECOOP Project and was further developed in a cooperation with COSYNA partners. We thank A. Barth, A. Port and K. Wahle for stimulating discussions on data analysis and data assimilation issues, as well as F. Ziemer for his support in the observational part. We acknowledge the use of MARNET data provided by BSH.

Edited by: G. Korotaev

\section{References}

Backhaus, J. O. and Maier-Reimer, E.: On seasonal circulation in the North Sea, in: North Sea Dynamics, edited by: Sündermann, J. and Lenz, W., Springer-Verlag, Berlin, Heidelberg, New York, 693 pp., 1983.

Barrick, D. E., Evans, M. W., and Weber, B. L.: Ocean surface currents mapped by radar, Science, 198(4313), 138-144, 1977.

Barth, A., Alvera-Azcárate, A., and Weisberg, R.: Assimilation of high-frequency radar currents in a nested model of the West Florida Shelf, J. Geophys. Res., 113, C08033, doi:10.1029/2007JC004585, 2008.

Barth, A., Alvera-Azcárate, A., Gurgel, K.-W., Staneva, J., Port, A., Beckers, J.-M., and Stanev, E. V.: Ensemble perturbation smoother for optimizing tidal boundary conditions by assimilation of High-Frequency radar surface currents - application to the German Bight, Ocean Sci., 6, 161-178, doi:10.5194/os-6161-2010, 2010.

Barth, A., Alvera-Azcárate, A., Beckers, J. M., Staneva, J., Stanev, E. V., and Schulz-Stelleneth, J.: Correcting surface winds by assimilating high-frequency radar surface currents in the German Bight, Ocean Dynam., 61(5), 599-610, doi:10.1007/s10236-010-0369-0, 2011. 
Becker, G. A., Giese, H., Isert, K., König, P., Langenberg, H., Pohlmann, T., and Schrum, C.: Mesoscale variability in the German Bight, Deut. Hydrogr. Z., 51(2), 155-179, 1999.

Bell, M. J., Lefèbvre, M., Le Traon, P.-Y., Smith, N., and WilmerBecker, K.: GODAE: the global Ocean data assimilation experiment, Oceanography, 22(3), 14-21, 2009.

Bennett, A. F.: Inverse Methods in Physical Oceanography, Cambridge University Press, New York, 1992.

Breivik, O. and Saetra, O.: Real time assimilation of HF radar currents into a coastal ocean model, J. Mar. Syst., 28, 161-182, 2001.

Burchard, H. and Bolding, K.: GETM - a general estuarine transport model, Tech. rep., European Comission, no EUR 20253 EN, printed in Italy, 2002.

Chapman, R., Shay, L. K., Graber, H., Edson, J. B., Karachintsev, A., Trump, C. L., and Ross, D. B.: On the accuracy of HF radar surface current measurements: intercomparison with shipbased sensors, J. Geophys. Res., 102, 18737-18748, 1997.

Crombie, D. D.: Doppler spectrum of sea echo at $13.56 \mathrm{Mc} / \mathrm{s}, \mathrm{Na}-$ ture, 175, 681-682, 1955.

De Mey, P. and Proctor, R.: Assessing the value of GODAE products in coastal and shelf seas, Ocean Dynam., 59(1), 1-2, 2009.

Dick, S. and Kleine, E.: The BSH new operational circulation model using general vertical co-ordinates, Environ. Res. Eng. Manag., 3(41), 18-24, 2007.

Dick, S. K., Kleine, E., Müller-Navarra, K., Klein, S. H., and Komo, H.: The operational circulation model of BSH (BSHcmod) model description and validation, Report 29, Bundesamt für Seeschifffahrt und Hydrographie (BSH), Hamburg, 2001.

Donlon, C. J., Casey, K. S., Robinson, I. S., Gentemann, C. L., Reynolds, R. W., Barton, I., Arino, O., Stark, J., Rayner, N., Le Borgne, P., Poulter, D., Vazquez-Cuervo, J., Armstrong, E., Beggs, H., Llewelly-Jones, D., Minnett, P. J., Merchant, C. J., and Evans, R.: The GODAE high resolution sea surface temperature pilot project, Oceanography, 22(3), 34-45, 2009.

Doerffer, R. and Schiller, H.: The MERIS case 2 water algorithm, Int. J. Remote Sens., 28, 517-535, 2007.

Droppert, L. J., Cattle, H., Stel, J. H., and Behrens, H. W. A.: The NOOS Plan: North West Shelf Operational Oceanographic System, 2002-2006, Vol. 18, Southampton Oceanography Centre, Southampton, ISBN 0-904175-46-4, 2000.

Emery, B. M., Washburn, L., and Harlan, J. A.: Evaluating radial current measurements from CODAR high-frequency radars with moored current meters, J. Atmos. Ocean. Tech., 21, 1259-1271, 2004.

Glenn, S. and Schofield, O.: Growing a distributed ocean observatory: our view from the COOL room, Oceanography, 22(2), 128-145, 2009.

Gough, M. K., Garfield, N., and McPhee-Shaw, E.: An analysis of HF radar measured surface currents to determine tidal, wind-forced, and seasonal circulation in the Gulf of the Farallones, California, United States, J. Geophys. Res., 115, C04019, doi:10.1029/2009JC005644, 2010.

Grayek, S., Staneva, J., Schulz-Stellenfleth, J., Petersen, W., and Stanev, E. V.: Use of FerryBox surface temperature and salinity measurements to improve model based state estimates for the German Bight, J. Mar. Syst., 88(1), 45-59, doi:10.1016/j.jmarsys.2011.02.020, 2011.

Gurgel, K.-W., Antonischki, G., Essen, H.-H., and Schlick, T.:
Wellen Radar (WERA): a new ground wave HF radar for ocean remote sensing, Coast. Eng., 37, 219-134, 1999.

Horstmann, J. and Koch, W.: Comparison of SAR wind field retrieval algorithms to a numerical model utilizing ENVISAT ASAR data, IEEE T. Geosci. Remote, 30(3), 508-515, 2005.

Ivanov, L. M. and Melnichenko, O. V.: Determination of mesoscale surface currents in shallow-water regions according to the data of high-frequency radar measurements, Phys. Oceanogr., 15, 92 104, 2005.

Janssen, F., Schrum, C., and Backhaus, J.: A climatological data set of temperature and salinity for the Baltic Sea and the North Sea, Deut. Hydrogr. Z., supp., 9, 5-245, 1999.

Kim, S. Y., Terril, E., and Cornuelle, B.: Objectively mapping HF radar-derived surface current data using measured and idealized data covariance matrices, J. Geophys. Res., 112, C06021, doi:10.1029/2006JC003756, 2007.

Koch, W.: Directional analysis of SAR images aiming at wind direction, IEEE TGARS, 42, 702-710, 2004.

Korres, G., Nittis, K., Hoteit, I., and Triantafyllou, G.: A high resolution data assimilation system for the Aegean Sea hydrodynamics, J. Mar. Syst., 77(3), 325-340, 2009.

Kurapov, A. L., Egbert, G. D., Allen, J. S., Miller, R. N., Erofeeva, S. Y., and Kosro, P. M.: The $\mathrm{M}_{2}$ internal tide off Oregon: inferences from data assimilation, J. Phys. Oceanogr., 33, 17331757, 2003.

Lehner, S., Horstmann, J., Koch, W., and Rosenthal, W.: Mesoscale wind measurements using recalibrated ERS SAR images, J. Geophys. Res., 103, 7847-7856, 1998.

Lewis, J. K., Shulman, I., and Blumberg, A. F.: Assimilation of Doppler radar current data into numerical ocean models, Cont. Shelf Res., 18, 541-559, 1998.

Liu, Y., Weisberg, R. H., Merz, C. R., Lichtenwalner, S., and Kirkpatrick, G. J.: HF radar performance in a low-energy environment: CODAR SeaSonde experience on the West Florida Shelf, J. Atmos. Ocean. Tech., 27(10), 1689-1710, 2010.

Oke, P. R., Allen, J. S., Miller, R. N., Egbert, G. D., and Kosro, P. M.: Assimilation of surface velocity data into a primitive equation coastal ocean model, J. Geophys. Res., 107, 3122, doi:10.1029/2000JC000511, 2002.

Paduan, J. D. and Rosenfeld, L. K.: Remotely sensed surface currents in Monterey Bay from shore-based HF radar (Coastal Ocean Dynamics Application Radar), J. Geophys. Res., 101, 20669-20686, 1996.

Paduan, J. D. and Shulman, I.: HF radar data assimilation in the Monterey Bay, J. Geophys. Res., 109, CO7S09, doi:10.1029/2003JC001949, 2004.

Petersen, W., Colijn, F., Hydes, D., and Schröder, F.: FerryBox: from on-line oceanographic observations to environmental information. EU Project FerryBox 2002-2005, EuroGOOS Publ., 25, 36, 2007.

Petersen, W., Schroeder, F., and Bockelmann, F.-D.: FerryBox application of continuous water quality observations along transects in the North Sea, Ocean Dynam., doi:10.1007/s10236-0110445-0, 2011.

Pleskachevski, A., Dobrinin, M., Babanin, A., Günther, H., and Stanev, E. V.: Turbulent mixing due to surface waves indicated by remote sensing of suspended particulate matter and its implementation into coupled modeling of waves, turbulence and circulation, J. Phys. Oceanogr., 41(4), 708-724, 
doi:10.1175/2010JPO4328.1, 2011.

Port, A., Gurgel, K. W., Staneva, J., Schulz-Stellenfleth, J., and Stanev, E. V.: Tidal and wind-driven surface currents in the German Bight: HFR observations versus model simulations, Ocean Dynam., doi:10.1007/s10236-011-0412-9, 2011.

Prandle, D.: The Fine-structure of nearshore tidal and residual circulations revealed by H. F. radar surface current measurements, J. Phys. Oceanogr., 17, 231-245, 1987.

Proctor, R. and Howarth, M.: Coastal observatories and operational oceanography: a European perspective, Mar. Technol. Soc. J., 42(3), 10-13, 2008.

Roussenov, V., Stanev, E. V., Artale, V., and Pinardi, N.: A seasonal model of the Mediterranean Sea general circulation, J. Geophys. Res., 100(C7), 13515-13538, 1995.

Schiller, R. and Doerffer, R.: Improved determination of coastal water constituent concentrations from MERIS data, IEEE T. Geosci. Remote, 43, 1585-1591, 2005.

Schofield, O. and Glenn, S.: Introduction to special section: coastal ocean observatories, J. Geophys. Res., 109(C12S01), 1-3, 2004.

Schulz-Stellenfleth, J. and Stanev, E. V.: Statistical assessment of ocean observing networks - a study of water level measurements in the German Bight, Ocean Model., 33, 270-282, doi:10.1016/j.ocemod.2010.03.001, 2010.

Schulz-Stellenfleth, J., Wahle, K., Staneva, J., Seemann, J., Cyseswki, M., Gurgel, K. W., Schlick, T., Ziemer, F., and Stanev, E. V.: Nutzung eines HF-Radarsystems zur Beobachtung und Vorhersage von Strömungen in der Deutschen Bucht im Rahmen von COSYNA, Nachrichten der Deutschen Gesellschaft für Meereskunde (DGM), 3/10, 3-8, 2011.

Scott, R. K., Allen, J. S., Egbert, G. D., and Miller, R. N.: Assimilation of surface current measurements in a coastal ocean model, J. Phys. Oceanogr., 30, 2359-2378, 2000.

Seim, H.: Ocean observing systems: regional experience yields global lessons, Mar. Technol. Soc. J., 42(3), 3, 2008.
Sentchev, A., Yaremchuk, M., and Lyard, F.: Residual circulation in the English Channel as a dynamically consistent synthesis of shore-based observations of sea level and currents, Cont. Shelf Res., 26, 1884-1904, 2006.

Shay, L. K., Lentz, S. J., Graber, H. C., and Haus, B. K.: Current structure variations detected by high-frequency radar and vectormeasuring current meters, J. Atmos. Ocean. Tech., 15, 237256, 1998.

Shay, L. K., Martinez-Pedraja, J., Cook, T. M., Haus, B. K., and Weisberg, R. H.: High frequency radar surface current mapping using WERA, J. Atmos. Ocean. Tech., 24, 484-503, 2007.

Soetje, K. C. and Brockmann, C.: An operational numerical model of the North Sea and the German Bight, in: North Sea Dynamics, edited by: Sündermann, J. and Lenz, W., Springer-Verlag, Berlin, Heidelberg, New York, 693 pp., 1983.

Stanev, E. V., Wolff, J.-O., Burchard, H., Bolding, K., and Flöser, G.: On the circulation in the East Frisian Wadden Sea: numerical modeling and data analysis, Ocean Dynam., 53, 27$51,2003$.

Staneva, J., Stanev, E. V., Wolff, J.-O., Badewien, T. H., Reuter, R., Flemming, B., Bartholomae, A., and Bolding, K.: Hydrodynamics and sediment dynamics in the German Bight. A focus on observations and numerical modeling in the East Frisian Wadden Sea, Cont. Shelf Res., 29, 302-319, 2009.

Stewart, R. and Joy, J.: HF radio measurements of surface currents, Deep-Sea Res., 21, 1039-1049, 1974.

Sündermann, J. and Lenz, W.: North Sea Dynamics, SpringerVerlag, Berlin-New York, 1983.

Wahle, K. and Stanev, E. V.: Consistency and complementarity of different coastal ocean observations: A neural network-based analysis for the German Bight, Geophys. Res. Lett., 38, L10603, doi:10.1029/2011GL047070, 2011.

Yaremchuk, M. and Sentchev, A.: Mapping radar-derived sea surface currents with a variational method, Cont. Shelf Res., 29, 1711-1722, 2009. 